\title{
LINKING MODELED AND EXPERIMENTALLY MEASURED INTERACTION STRENGTHS BETWEEN AN EXOTIC SNAIL AND ALGAE IN RIVERS IN Yellowstone National PARK
}

\author{
ROBERT O. HALL, JR. $\uparrow$ DEPARTMENT OF ZOOLOGY AND PHYSIOLOGY \\ UNIVERSITY OF WYOMING † LARAMIE
}

\author{
MARK F. DYBDAHL $\downarrow$ DEPARTMENT OF BIOLOGICAL SCIENCES \\ OHIO UNIVERSITY $\uparrow$ ATHENS
}

\section{INTRODUCTION}

Exotic species are one of the largest humancaused threats to ecosystems and are becoming a central focus of research for e cologists. We do not know what factors allow exotic species to invade, nor can we predict what effects the exotic species will have once it has invaded. Invasive species, including mollusks, have greatly affected processes in freshwater ecosystems.

A recent mollusk invader to North America is the New Zealand mud snail, Potamopyrgus antipodarum. It is a small snail (ca. $4 \mathrm{~mm}$ long) in the family Hydrobiidae. Potamopyrgus has recently invaded the Snake and Madison Rivers and the Great Lakes In the Madison River, it is numerically dominating the benthos in certain locations with densities over 300,000 individuals $/ \mathrm{m}^{2}$ with a corresponding biomass of $30 \mathrm{~g} / \mathrm{m} 2$ (R. Hall, unpublished data). Because mud snails have high biomass and potentially high secondary production, they may alter algal species composition, and lower algae biomass a nd production in rivers. Algae form the base of the food web in these rivers; hence, mud snails may be competing with other invertebrates by lowering algae biomass as has been shown for a caddisfly grazer (Kohler and Wiley 1997). It is relatively straightforward to measure grazer impact on algae population using small-scale experiments. However, it is harder to scale up these estimates to whole-river primary production because we cannot manipulate snail densities at this scale. From a management $\mathrm{p}$ erspective, we cannot do experiments every time a prediction is needed, e.g. when this snail invades a different river. $\mathrm{F}$ or this reason to p redict impacts based on knowing snail and algae biomass using a modeling approach may become useful.

Ecologists are just beginning to link energy flow with experimentally measured interaction strengths. Recently Wootton (1997) provided a theoretical means to link energy flow with experimentally measured interaction strength for bird foraging in the rocky intertidal zone. He estimated parameters of a Lotka-Volterra predator-prey model using consumption rate estimates. He then compared these estimated parameters with those measured (using the same units) using experiments. He found a positive correlation between the two suggesting that it is possible to predict interaction strength from energy flow from the consumer to the resource.

The objective of this study is to estimate interaction strength between exotic mud snails and 
periphyton by using the modeling approach developed by Wootton (1997) and to test these estimates by using controlled field experiments.

\section{$\uparrow \quad$ METHODS}

Study sites were the Upper Snake River near the South entrance of Yellowstone Park and the Firehole River downstream of Ojo Caliente. The Snake river is a cobble-bottom stream with a large alluvial channel. We performed one experiment during Aug. 2000. The Firehole River is a geothermally influenced spring stream with extensive macrophyte beds, where we conducted 2 experiments during Aug. 2000. Snail densities are high in the Madison River, and this site was the location of previous experiments (B. Kerans Montana State, M. Dybdahl, Ohio U.) to examine competition. Snails are less dense in the Snake River, but I have observed strongly reduced algal biofilms on rock that they have colonized in backwater channels.

Modeling approach. Wootton (1997) outlined an approach whereby theoretical estimates of interaction strength can be compared with those measured from experiments.

Given a standard predator-prey model for one predator feeding on one prey:

$\frac{d N}{d t}=a N-c N S$

where $\mathrm{N}=$ algae biomass, $\mathrm{S}=$ snail biomass and $\mathrm{c}$ the per capita interaction strength of snails on algae. The consumption rate of algae (biomass of algae $\cdot$ area $^{-1}$. time $^{-1}$ ) is e qual to - c SN. The impact of the grazer species on algae is $\mathrm{cS}$ which has units of $\left(\mathrm{time}^{-1}\right)$ and is equal to the ingestion rate divided by prey biomass per unit area. This impact represents the fraction of algae removed per unit time by the grazing snails. Per biomass impact (c) can be determined by dividing $\mathrm{CS}$ by predator biomass, giving units of time $^{-1} \cdot$ (predator biomass/area) $)^{-1}$ (Wootton 1997).

By multiplying $\mathrm{cS}$ by some elapsed time $\mathrm{t}$ we can estimate the species impact of snails on algae over that time. This value can be directly compared with results from experiments by using a discrete time variant of eq 1 .

$$
N_{t}=N_{0} \exp \{(a-c S) t\}
$$

where $\mathrm{N}_{t}$ is algae biomass at some time $t$ and $\mathrm{N}_{\mathrm{o}}$ is initial algae biomass. The effect of snails on algae can be shown as the ratio of algae biomass $\left(\mathrm{N}_{\mathrm{t}}\right)$ with $(\mathrm{S}>$ $0)$ and without $(S=0)$ grazing snails. By setting up this ratio and simplifying:

$$
\ln \left(\frac{N_{t, S>0}}{N_{t, S=0}}\right)=-c S t
$$

Thus the left-hand side of eq 3 , which is estimated experimentally, can be compared directly with $\mathrm{cSt}$ estimated from consumption rates of snails on algae (Wootton 1997).

In each experimental unit (see below) we estimated consumption rates of algal biomass as a whole and of individual species of algae using the trophic basis of production method (Benke and Wallace 1980, Hall et al. in press). By knowing secondary production of the species and its food sources, flow from each food type i to consumer $\mathrm{j}$ (Fij in $\mathrm{mg}$ AFDM m $\mathrm{m}^{-2} \mathrm{~d}^{-1}$ ) was calculated by using the following equation:

$F_{i j}=\left(B_{i} P_{j}\right) /\left(A_{i} N P E\right)$

where $\mathrm{P}_{\mathrm{j}}$ is production of consumer $\mathrm{j}$ in $\mathrm{mg}$, AFDM $\mathrm{m}^{-2} \mathrm{~d}^{-1}$ and $\mathrm{AE}_{\mathrm{i}}$ is assimilation efficiency for algae (assumed to be 0.3), and NPE is net production efficiency (assumed to be 0.4) (Benke and Wallace 1980).

Consumption rates and experimental procedure. Snail production was measured by multiplying snail biomass per unit area by a measured growth rate and fecundity rate for 5 size classes of s nails at each of the sites. We estimated growth rates by caging snails in small enclosures for three weeks and measuring change in biomass and juvenile snail production.

We measured interaction strength directly by manipulating snail density and observing changes in algae populations. We manipulated snails by using 8-9 plastic sandwich trays with window screen covering the top and sides of each tray. Each tray 
held $64-5 \mathrm{~cm}$ rocks and were bolted to a brick which held them in the current. To each of 2 trays we added $0,50,100$, or 200 snails.

After 7 days we removed from the trays and collected all snails to measure biomass and consumption $\mathrm{r}$ ates. P rimary p roduction on the rocks was estimated by putting rocks into light and dark in situ chambers and measuring consumption/ production of dissolved oxygen after a 1-hour incubation. After the production estimates, algae were brushed off rocks using a toothbrush and water. A sample of the resulting slurry was analyzed for chlorophyll, which is an indicator of algal biomass. We estimated algal biomass from chlorophyll a assuming a $\mathrm{C} / \mathrm{Chl}$ ratio of 50 .

\section{RESULTS}

Primary production on the chambers decline as a function of snail density in each of the cages (Fig. 1). Slopes for the Firehole river were steep and nearly equal, showing the impact varied little between the two experiments. Production in the Snake River declined much less sharply, showing lower per capita impact of the snails.

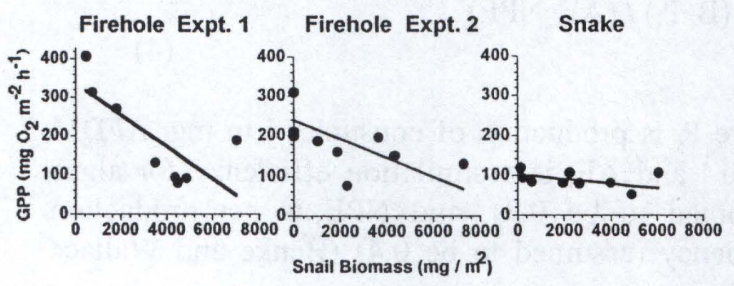

Figure 1. Primary production declined as a function of snail biomass in the experimental chambers. Lines are least-squares linear regressions and are statistically significant $(P<0.05)$

Measured interaction strength was positively related to predicted interaction strength showing that we could predict the direction of interaction by using consumption rate estimates. However the slopes of all of these relationships were $<1$ showing that we predicted much stronger declines than we measured. Also, based on the slopes of each of these lines, it shows that snails in the Snake River have similar impacts relative to those in the Firehole River. (Fig. 2)

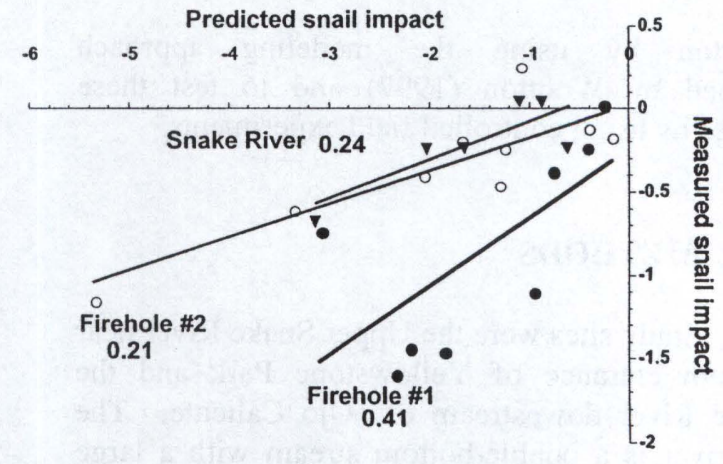

Figure 2. Predicted snail impact is positively related to measured snail impact. Predicted interaction strength is $\ln \left(\frac{N_{t, S>0}}{N_{t, S=0}}\right)$ which is estimated experimentally. Measured impact is cSt estimated from consumption rates of snails on algae(see text for details) Filled circles and hollow circles are data for Firehole River experiments 1 and 2 and triangles a re for the Snake River experiment. Lines are least-squares linear regressions and are statistically significant for each fit. Numbers are the slope of each line and show that measured impact is smaller than predicted impact.

It is possible that high algal turnover explains why we predict higher impact than we observe; replacement of algal biomass through rapid growth may lessen impact of grazers on their biomass. Therefore we compared the ratio of snail consumption / algal production with measured impact. High consumption/production ratios should represent higher impact of snails on algae. Production/consumption was strongly negatively related to measured snail impact showing that we can predict the direction, but not magnitude, of impact between snails and algae. Interestingly, this analysis shows that snails in the Snake River have much lower impact on algae than those in the Firehole River, (Fig. 3) which is what we observed in Fig 1.

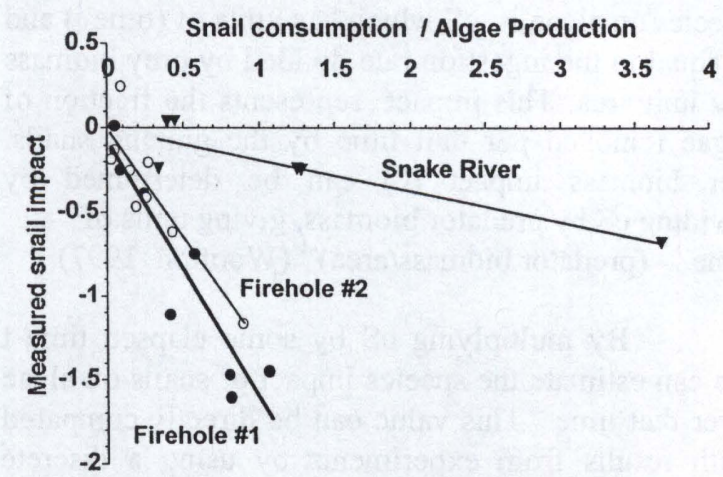

Figure 3. Snail consumption / algal production is negatively related to measured impact. Filled circles and hollow circles are data for Firehole River experiments 1 and 2 and triangles are for the Snake River experiment. Lines are least-squares linear regressions and are statistically significant for each fit. 


\section{DISCUSSION}

Although some have argued that consumption rates cannot be related to experimentally measured interaction strength (Paine $1980,1992)$ we showed here that indeed they can as Wootton (1997) found. However we add the caveat that we were not able to relate the magnitudes exactly. This effect is most likely because algae can turn over their biomass very quickly and they are probably able to keep up with invertebrate grazing without a large decrease in biomass as also found by Ruesink (1998). By relating algae consumption / algae production we are able to account for this high turnover by measuring growth rate (primary production) itself. Unfortunately, this approach is not developed in the theoretical context of Wootton (1997), and because the units are different, we have no $a$ priori basis to relate production/consumption with measured impact. However this second approach better showed the lower impact of snails on algae in the Snake River compared with the Firehole River.

Impact of snails on algae was much lower in the Snake River than the Firehole river, despite the fact that we predicted much stronger impacts there based on consumption / production. Our predictions may be in error if snails are consuming nonliving detritus instead of algae in the Snake River. That is, inputs of sestonic detritus may have been subsidizing snails there such that algal biofilms were less affected. Also, algae in the Snake river may be resistant to grazing, and therefore less impacted than those in the Firehole River. This variation in impact means that, as of yet, we cannot a priori predict snail impact in different river because the per-biomss impact varies so greatly between these 2 rivers.

\section{ACKNOWLEDGEMENTS}

We thank Mike Marshall, Chelsea Crenshaw, Michelle Baker, Leslie Riley, and Jack Goldstein for assisting with fieldwork. This research was supported by a Faculty Grant-in-Aid from the office of the Vice President for Research, University of Wyoming.

\section{$\downarrow$ REFERENCES}

Benke, A. C., and J. B. Wallace. 1980. Trophic basis of production among net-spinning caddisflies in a southern Appalachian stream. Ecology 61:108-118.

Kohler, S. L. and M. L. Wiley. 1997. Pathogen outbreaks reveal large-scale effects of competition in aquatic communities. Ecology 78:2164-2176.

Paine, R. T. 1980. Food webs: linkage, interaction strength, and community infrastructure. Journal of Animal Ecology 49:667-685.

Paine, R. T. 1992. Food-web analysis through field measurement of per capita interaction strength. Nature 355:73-75.

Ruesink, J. L. 1998. Variation in per capita interaction strength: thresholds due to nonlinear dynamics and nonequilibrium conditions. Proceedings of the National Academy of Sciences 95:6843-6847.

Wootton, J. T. 1997. Estimates and tests of per-capita interaction strength: diet abundance and impact of intertidally-foraging birds. Ecological Monographs 67:45-64. 